\title{
Clinton's science policies and personnel have yet to emerge as he prepares for presidency
}

Washington. How high on the pecking order will research be in a Clinton administration? It was too soon to answer that question last week as US president-elect Bill Clinton began preparing to move into the White House.

Science was not an issue during the campaign, although both Clinton and President George Bush paid lip service to the importance of research. (Ross Perot hardly addressed the topic.) Interest in the subject was dwarfed by concern about reviving the US economy, reducing the federal budget deficit and creating a more comprehensive and less expensive health care system. As a result, anyone who pretends to know what Clinton thinks about science is putting on airs and, also, is quite likely to be wrong.

Nevertheless, there is already much speculation about the next four years. Many are optimistic about the prospects for science, although there is concern that research may have a hard time competing against other worthy demands on scarce federal dollars and, more specifically, against efforts to improve US manufacturing and repair the crumbling infrastructure. At the same time, the air is filled with anticipation about a successor to D. Allan Bromley as the presi- dent's science adviser and whether Walter Massey and Bernadine Healy will retain their jobs as directors of the National

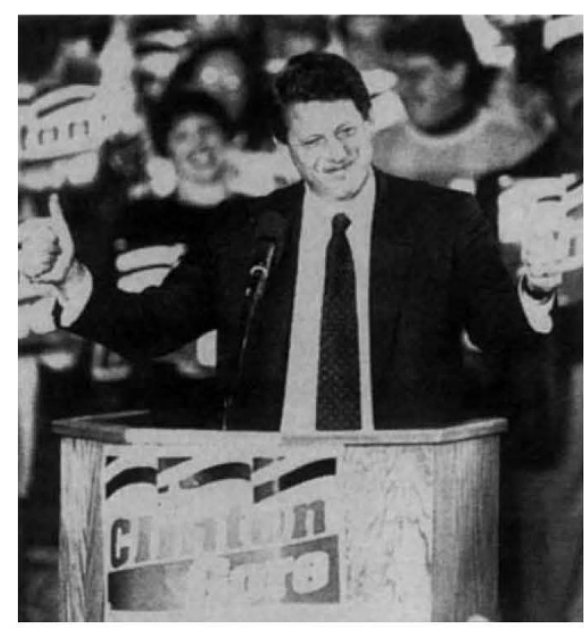

Al Gore is ready to implement whatever science and technology policy a Clinton administration decides it wants.

Science Foundation (NSF) and the National Institutes of Health (NIH) respectively.

Looming as a wild card is vice president- elect Al Gore. Referred to derisively as "Ozone" by the Bush campaign because of his interest in environmental matters during his 16 years in Congress, Gore is widely expected to be a one-man clearinghouse for the president on science and technology issues. But it is not clear how Gore will do that.

"The last thing we want is another layer of bureaucracy", says one campaign adviser. "Gore doesn't want to second-guess the science adviser, although he'll want to be in the room when the science adviser talks with the president."

One possible solution is that Gore might become head of what the Clinton campaign has called an Economic Security Council, a body similar to the National Security Council that would add a technological component to the traditional review of domestic issues. Such a position would give him an opportunity to apply his knowledge and the political clout to insist that agencies carry out what the president wants.

"We don't want to do what the Bush administration did with Dan Quayle and the [National] Space Council by setting up a structure separate from the White House and NASA", says the campaign aide. "They delayed policies; we want to find a way to carry out the president's program, not get in the way."

Although many names have been offered as Bromley's successor as science adviser and director of the Office of Science and Technology Policy, none has as yet caught the attention of the president-elect's transition team. Many are expecting a person from industry, in particular one experienced in manufacturing. Others believe that it is time for someone from the life sciences, perhaps biotechnology, to assume a job traditionally held by a physicist orientated towards national defence. Few expect Clinton's science adviser to be a career academic, as is Bromley.

As for the White House science office itself, Clinton's campaign rhetoric suggests that it will play an active role in coordinating technology initiatives. But reality says otherwise: the office is already too small to take on such responsibility, and Clinton has promised to reduce the federal work force by 100,000 . "A bigger science office just isn't in the cards", says one aide.

What of Massey and Healy? Opinion is divided as to whether a decision to replace them would mean that Clinton has politicized the offices (Massey's term runs until 1997, and Healy serves at the pleasure of the president) or that he simply prefers fresh faces. In their favour, Healy's emphasis on the need for NIH to serve society, not sci- 